\title{
Antisense Expression of MdTFL1, a TFL1-like Gene, Reduces the Juvenile Phase in Apple
}

\author{
Nobuhiro Kotoda', Hiroshi Iwanami, Sae Takahashi, and Kazuyuki Abe \\ Department of Apple Research, National Institute of Fruit Tree Science, Incorporated Administrative \\ Agency, National Agriculture and Bio-oriented Research Organization (NARO), Shimo-kuriyagawa, \\ Morioka 020-0123, Japan
}

\begin{abstract}
AdDitional InDEX words. CETS, fruit breeding, genetic transformation, juvenility, Malus $\times$ domestica, precocious flowering
Aвstract. Because fruit trees such as apple (Malus $\times$ domestica Borkh.) flower and set fruit only after an extended juvenile phase lasting several years, efficient breeding of fruit trees is limited. We previously suggested that MdTFL1

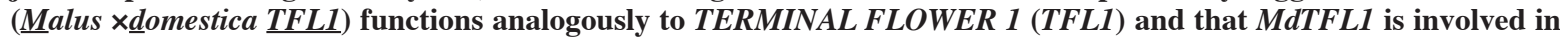
the maintenance of the juvenile/vegetative phase in apple. To clarify the function of MdTFL1 in apple, we produced transgenic 'Orin' apple trees expressing MdTFL1 antisense RNA. One of them flowered only 8 months after the transfer to the greenhouse, whereas the nontransformed control plants have not flowered in nearly 6 years. As expected, the expression of endogenous MdTFL1 was suppressed in the transgenic lines that showed precocious flowering. In addition, the expression level of the transgene was correlated with the reduction of the juvenile phase. These findings confirm that MdTFL1 functions like TFL1 and that MdTFL1 maintains the juvenile and vegetative phase in apple. Flower organs of the transgenic apple trees were normal in appearance, and a precocious flowering transgenic line set fruit and seeds. Interestingly, some flowers of the transgenic apple trees developed without undergoing dormancy. The expression of MdTFL1 in apple may affect flower development as well as flower induction.
\end{abstract}

In the development of all woody plants from seed, there is a so-called juvenile phase, lasting up to 30 to 40 years in certain forest trees, during which flowering does not occur and cannot be induced under normal conditions (Hackett, 1985). In the fruit industry, it is important to accelerate flowering by reducing the juvenile or vegetative phase of the trees after planting in order to facilitate the earliest possible production of fruit. Breeding fruit trees such as apple often takes more than 20 years, including periods of cross pollination, seedling selection, and regional trials to produce varieties that meet consumer demands. For example, the 'Fuji' apple, one of the most popular apple cultivars in the world (O'Rourke et al., 2003), first set fruit 12 years after being sowed, and it was 23 years before it was released as a cultivar (Sadamori et al., 1963). Generally, the juvenile phase in apple lasts 6 to 12 years (Visser, 1964; Zimmerman, 1972).

In fruit breeding, various practical techniques have been considered to accelerate the flowering and fruiting of seedlings. The basic idea is to grow the seedlings rapidly from the germination stage to the transition to flowering (Aldwinckle, 1975; Visser, 1964). In apple, grafting the seedlings onto dwarfing rootstocks such as 'Malling 9' ('M.9') and 'Malling 27' ('M.27') will usually bring earlier flowering by 1 or 2 years (Visser, 1964, 1973). Grafting seedlings onto bearing trees (top grafting), ringing, scoring, bark inversion, root pruning, and spraying with growth retardants may stimulate earlier flowering when applied to older seedlings, but in these conditions, the juvenile phase probably has already passed, and the seedlings are in transition (Kender,

Received for publication 31 Mar. 2005. Accepted for publication 2 July 2005. We thank Hiroaki Ichikawa, the National Institute of Agrobiological Sciences, for providing the binary vector pSMAK251, and Tomoko Sekita, the National Institute of Fruit Tree Science, for technical assistance. This work was supported by the "Development of innovative plants and animals using transformation and cloning" project of MAFF and the Program for Promotion of Basic Research Activities for Innovative Biosciences (PROBRAIN). This publication constitutes contribution number 1369 of the National Institute of Fruit Tree Science.

1Corresponding author; e-mail address: koto@affrc.go.jp
1974; Zimmerman, 1972). Based on our experience, it would, however, be difficult to reduce the juvenile phase of apple seedlings to $<4$ years under normal growing conditions even if they are grafted on the dwarfing rootstock. The length of the juvenile phase is influenced more by genetic factors than by environmental factors. Significant correlations have been found between the length of the juvenile phase and parent characteristics such as growth rate and the length of the vegetative phase (Lavi et al., 1992; Visser, 1965).

The most striking advances in our understanding of the genetic control of the timing of flowering have come from the study of arabidopsis [Arabidopsis thaliana (L.) Heynh.] (Levy and Dean, 1998; Piñeiro and Coupland, 1998), and several genes such as LEAFY (LFY), APETALAI (API), TERMINAL FLOWER 1 (TFL1), and FLOWERING LOCUS T (FT), which control flowering time, have been isolated from arabidopsis (Bradley et al., 1997; Kardailski et al., 1999; Kobayashi et al., 1999; Mandel etal., 1992; Ohshima et al., 1997; Weigel et al., 1992). Over-expression of $L F Y, A P 1$, or $F T$ shortens the vegetative phase, causing early flowering(Kardailski et al., 1999; Kobayashi et al., 1999; Mandel et al., 1995; Weigel and Nilsson, 1995), whereas over-expression of $T F L 1$ causes late flowering in transgenic arabidopsis (Ratcliffe et al., 1998). TFL1 plays a key role in the maintenance of the inflorescence meristem by preventing the expression of $L F Y$ and $A P 1$ (Ratcliffe et al., 1999). Apple orthologues of several of these genes such as AFL1, AFL2, MdAP1 (MdMADS5), and MdTFL1 have been isolated and characterized (Kotoda et al., 2000, 2002; Kotoda and Wada, 2005; Sung et al., 1999; Wada et al., 2002; Yao et al., 1999).

With the goal of elucidating the long juvenility of fruit trees, we are interested in regulatory genes, such as arabidopsis TFL1, snapdragon (Antirrhinum majus L.) CENTRORADIALIS (CEN), and tomato (Lycopersicum esculentum Mill.) SELF-PRUNING $(S P)$ genes, which maintain the vegetative phase and promote the emergence of shoots rather than flowers (Bradley et al., 1996; Pnueli et al., 1998), as well as genes such as $L F Y$ and $A P 1$, which promote flowering. Therefore, we isolated and characterized 
the apple gene MdTFL1, which is homologous to TFL1, and concluded that MdTFL1 functions like TFLI and is involved in the maintenance of juvenility in apple (Kotoda and Wada, 2005). $T F L 1 / C E N / S P$ are closely related members of the CETS family, a small gene family that encodes $23-\mathrm{kD}$ proteins, and they share sequence similarity with a group of mammalian phosphatidylethanolamine-binding proteins (PEPBs) (Bradley et al., 1996, 1997; Oshima et al., 1997; Pnueli et al., 1998). The FT gene also belongs to the CETS family, but it mediates signals for flowering antagonistically with its homologous gene, TFL1, and promotes flowering with $L F Y$ (Kardailsky et al., 1999; Kobayashi et al., 1999). In other species, a number of TFL1 homologues from tobacco (Nicotiana tabacum L.2), oilseed rape (Brassica napus L.), cabbage (Brassica oleracea L. var. capitata L.), ryegrass (Lolium perenne L.), rice (Oryza sativa L.), pea (Pisum sativum L.), and navel orange [Citrus sinensis (L.) Osbeck] have been cloned and characterized (Amaya et al., 1999; Foucher et al., 2003; Jensen et al., 2001; Mimida et al., 1999; Nakagawa et al., 2002; Pillitteri et al., 2004).

We describe here the precocious flowering of transgenic apple trees caused by the suppression of MdTFL1 in the first report on the extreme reduction of the juvenile phase in deciduous fruit trees.

\section{Materials and Methods}

Plant Materials. Micropropagated tissues of the apple cultivar Orin were used for Agrobacterium-mediated [A. tumefaciens (Smith \& Towns.) Conn.] transformation. The 'Orin' shoots were subcultured every 4 weeks in a proliferation medium [MurashigeSkoog (MS) medium containing B5 vitamin $\left(1.0 \mathrm{mg} \cdot \mathrm{L}^{-1}\right.$ nicotinic acid, $10 \mathrm{mg} \cdot \mathrm{L}^{-1}$ thiamine chloride, $1.0 \mathrm{mg} \cdot \mathrm{L}^{-1}$ pyridoxin, and 100 $\mathrm{mg} \cdot \mathrm{L}^{-1}$ myo-inositol), $1 \mathrm{mg} \cdot \mathrm{L}^{-1}(4.4 \mu \mathrm{M})$ 6-benzyl-aminopurine (BA), $0.1 \mathrm{mg} \cdot \mathrm{L}^{-1}(0.49 \mu \mathrm{M})$ indole-3-butyric acid (IBA), $3 \%(\mathrm{w} / \mathrm{v})$ sucrose, $0.7 \%(\mathrm{w} / \mathrm{v})$ agar ( $\mathrm{pH}$ 5.8)] at 23 to $25^{\circ} \mathrm{C}$ under long-day (LD) conditions ( $16 \mathrm{~h}$ light $/ 8 \mathrm{~h}$ dark). Transformed and nontransformed shoots of tissue culture were grafted to apple seedlings or 'JM8' ['Marubakaido' (Malus prunifolia Borkh. var. ringo Asami) $\times$ 'M.9'], an easy-cutting apple dwarfing rootstock (Soejima et al., 1998). Grafted apples were grown in an isolated greenhouse with the temperature set at 20 to $25^{\circ} \mathrm{C}$ during the growing season (from April to November). Thereafter, the temperature was shifted to below $7^{\circ} \mathrm{C}$ in the dormant season (from December to March). Liquid fertilizer was sprayed once per month.

CONSTRUCTION OF TRANSFORMATION VECTORS. The plasmid vector pUMDTFL1- (Kotoda and Wada, 2005) was cut with $X b a 1$ and $S a c I$, after which the released MdTFL1 cDNA fragment was ligated to the binary vector pSMAK251 cut with the same restriction enzymes in an antisense-oriented manner (Fig. 1). The characterization of pSMAK251, which contains genes for $\beta$-glucuronidase (GUS) and neomycin phosphotransferase II (NPTII) in its T-DNA region, will be published elsewhere (H. Ichikawa, unpublished). The product of the ligation was named pSMDTFL1.1- (35S::MdTFL1 antisense construct). The MdTFL1 antisense gene was driven by the cauliflower mosaic virus (CaMV) 35S promoter, and the vector conferred kanamycin resistance (Fig. 1A).

TrANSFORMATION OF APPLE. The apple cultivar Orin was transformed with A.tumefaciens strain EHA101 bearing pSMDTFL1.1. Agrobacterium tumefaciens was cultured overnight on a shaker in $20 \mathrm{~mL}$ liquid $\mathrm{LB}$ medium $\left(10 \mathrm{~g} \cdot \mathrm{L}^{-1}\right.$ tryptone, $5 \mathrm{~g} \cdot \mathrm{L}^{-1}$ yeast extract and $5 \mathrm{~g} \cdot \mathrm{L}^{-1} \mathrm{NaCl}, \mathrm{pH} 7.0$ ) with $100 \mathrm{mg} \cdot \mathrm{L}^{-1}$ trobicin (Pfizer Japan,
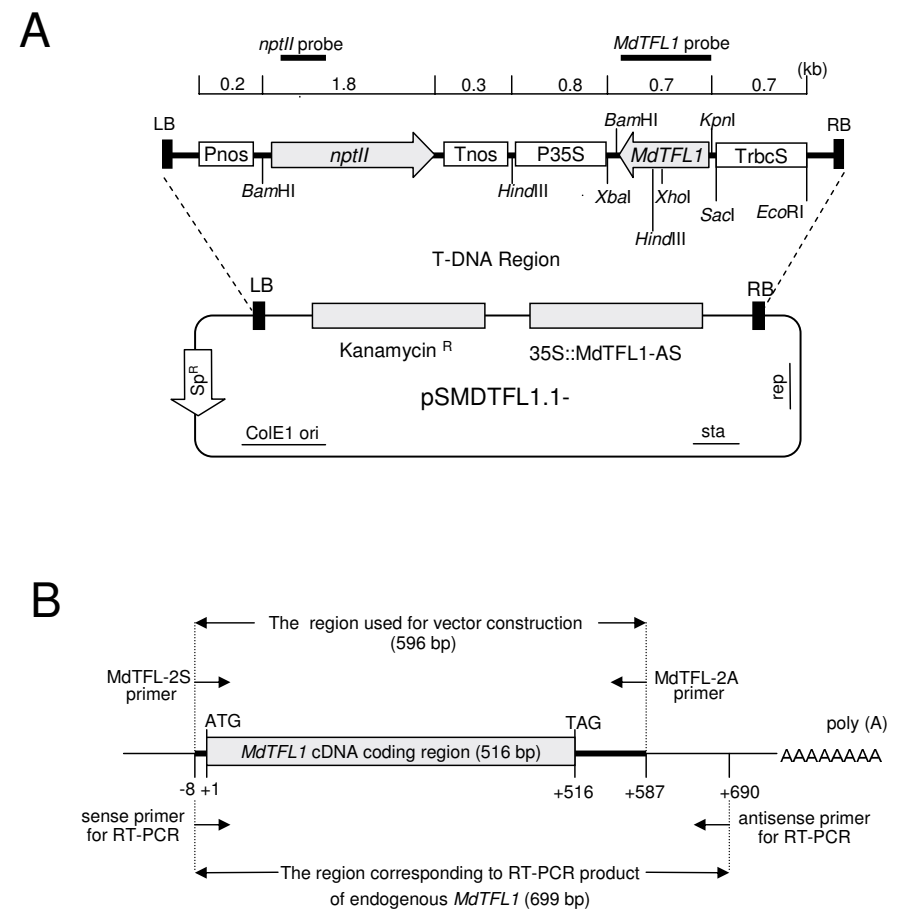

Fig. 1. Schematic representation of the transformation vector pSMDTFL1.1- and MdTFL1 cDNA used for vector construction. (A) MdTFL1 cDNA was inserted in the antisense orientation between the $\mathrm{XbaI}$ and $\mathrm{SacI}$ sites of the binary vector pSMAK251, giving rise to pSMDTFL1.1-. Regions of the probes to detect the nptII or MdTFLI gene are indicated by the bold lines above each gene; Pnos $=$ nos promoter, Tnos $=3^{\prime}$ region of nos, $\mathrm{P} 35 \mathrm{~S}=$ cauliflower mosaic virus $35 \mathrm{~S}$ promoter, $\mathrm{TrbcS}=3^{\prime}$ region of arabidopsis $r b c S-2 B$ gene, $n p t I I=$ neomycin phosphotransferase II gene, $\mathrm{LB}=$ left border, $\mathrm{RB}=$ right border, $\mathrm{SpR}$ $=$ spectinomycin/streptomycin resistance gene from Tn 7, ColE1ori $=$ ColE1 replication origin from $\mathrm{pBR} 322, \mathrm{sta}=$ region involved in plasmid stability, rep $=$ region essential for plasmid maintenance. $(\mathbf{B})$ Region between the positions -8 and +587 of $M d T F L 1$ cDNA used for vector construction. This DNA region (596 bp) can be amplified by a PCR with gene-specific primers MdTFL-2S and MdTFL-2A. For RT-PCR analysis; sense primer (position $=-8 \sim+15$ ) and antisense primer (position $=+670 \sim+690$ ) were used to detect endogenous MdTFL1 transcripts. The 699-bp DNA fragment was obtained as a reverse transcription (RT)-PCR product for endogenous $M d T F L 1$; $\mathrm{ATG}=$ initiation codon, $\mathrm{TAG}=$ stop codon. A box represents a coding region and a bold line including a box represents the region inserted into the binary vector pSMAK251.

Tokyo) at $28{ }^{\circ} \mathrm{C}$. After centrifugation $\left(2000 g_{\mathrm{n}}, 5 \mathrm{~min}\right)$, the pellet was resuspended in MS medium with $3 \%(\mathrm{w} / \mathrm{v})$ sucrose and 150 $\mu \mathrm{M}$ acetosyringone (3',5'-dimethoxy-4'-hydroxyacetophenone; Acros Organics, Geel, Belgium) and further diluted with this medium until an optical density (OD) of 0.5 to 0.8 at $600 \mathrm{~nm}$ was reached. Leaf explants of the apple cultivar Orin were infected with the inoculum for $30 \mathrm{~min}$, and then the leaf explants were transferred to a co-cultivation medium consisting of MS salt, 3.3 $\mathrm{mg} \cdot \mathrm{L}^{-1}(15 \mu \mathrm{M})$ thidiazuron (TDZ), $0.93 \mathrm{mg} \cdot \mathrm{L}^{-1}(5 \mu \mathrm{M})$ naphthaleneacetic acid (NAA), $29.4 \mathrm{mg} \cdot \mathrm{L}^{-1}(150 \mu \mathrm{M})$ acetosyringone, and $0.25 \%(\mathrm{w} / \mathrm{v})$ gelrite. After co-cultivation for 5 to $7 \mathrm{~d}$ at 22 to $25{ }^{\circ} \mathrm{C}$ in the dark, explants were transferred to an antibiotic selection medium consisting of MS salt, $3.3 \mathrm{mg} \cdot \mathrm{L}^{-1}(15 \mu \mathrm{M}) \mathrm{TDZ}$, $0.93 \mathrm{mg} \cdot \mathrm{L}^{-1}(5 \mu \mathrm{M}) \mathrm{NAA}, 25 \mathrm{mg} \cdot \mathrm{L}^{-1} \mathrm{kanamycin}$ monosulfate, $500 \mathrm{mg} \cdot \mathrm{L}^{-1}$ Claforan (Pharmacia and Upjohn Ltd., Tokyo), and $0.25 \%$ (w/v) Gelrite. When adventitious shoots appeared, cultures were transferred to an antibiotic selection medium containing $50 \mathrm{mg} \cdot \mathrm{L}^{-1} \mathrm{kanamycin}$ monosulfate and then incubated at $25^{\circ} \mathrm{C}$ with a 16 -h photoperiod $\left(30 \mu \mathrm{mol} \cdot \mathrm{m}^{-2} \cdot \mathrm{s}^{-1}\right)$. When the shoots had produced several leaves, they were excised and transferred to a proliferation medium containing $50 \mathrm{mg} \cdot \mathrm{L}^{-1} \mathrm{kanamycin}$ mono- 
sulfate. The transgene insertion was confirmed by a polymerase chain reaction (PCR) with specific primers for $n p t I I$ (NPTII-3S sense primer, 5'-GCC CTG AAT GAA CTG CAG GAC GAG GC-3'; NPTII-3Aantisense primer, 5’-GCAGGCATC GCCATG AGT CAC GAC GAG A-3’; PCR product, 411 bp) or MdTFL1 (MdTFL-2S sense primer, 5'-CTC TTA AAA TGA AAA GAG CC-3'; MdTFL-2Aantisense primer, 5'-TTC TCACAT GTCAAT AAG TT-3'; PCR product, 596 bp). The region amplified with primers (MdTFL-2S and -2A) for MdTFL1 is shown in Fig. 1B. Conditions of amplification for each primer set were as follows; 1 cycle of $300 \mathrm{~s}$ at $94{ }^{\circ} \mathrm{C}, 30$ cycles of 15 s at $94^{\circ} \mathrm{C}, 15 \mathrm{~s}$ at $65^{\circ} \mathrm{C}$ and $30 \mathrm{~s}$ at $72{ }^{\circ} \mathrm{C}$ for $n p t I I ; 1$ cycle of $300 \mathrm{~s}$ at $94{ }^{\circ} \mathrm{C}, 40$ cycles of $30 \mathrm{~s}$ at $94{ }^{\circ} \mathrm{C}, 30 \mathrm{~s}$ at $50{ }^{\circ} \mathrm{C}$, and $60 \mathrm{~s}$ at $72{ }^{\circ} \mathrm{C}$ for MdTFL1. Putatively transformed shoots were excised and transferred to a proliferation medium free of antibiotics.

DNA BLOT ANALYSIS. Genomic DNA was obtained from transgenic and nontransgenic 'Orin' apple leaves using the CTAB method as described by Kotoda et al. (2002). The DNA (10 $\mu \mathrm{g})$ was digested individually with either BamHI, EcoRI, HindIII, or $X b a \mathrm{I}$ according to the manufacturer's instructions (Takara Biomedicals, Tokyo) and then separated on $0.8 \%$ (w/v) SeaKem GTG agarose gel (Cambrex Bio Science, Rockland, Maine). The DNA bands were transferred to Hybond-N+ (Amersham Pharmacia Biotech, Buckinghamshire, UK) and hybridized with a digoxigenin (DIG)-labeled PCR probe encoding the nptII or MdTFLI gene (Fig. 1A). Primer sets used for DIG-labeled PCR probes of NPTII and MdTFLI were NPTII-3S and -3A, and MdTFL-2S and -2A, respectively (Fig. 1). DIG-labeled DNA Molecular-Weight Marker II (Roche Diagnostics, Mannheim, Germany) was used as a size marker. Hybridization was performed in DIG Easy Hyb (Roche Diagnostics) at $42{ }^{\circ} \mathrm{C}$ for $16 \mathrm{~h}$, followed by two rinses in $2 \times \mathrm{SSC}$ containing $1 \%(\mathrm{w} / \mathrm{v}) \mathrm{SDS}$ at room temperature for 5 min and two washes in $0.5 \times \mathrm{SSC}$ containing $1 \%(\mathrm{w} / \mathrm{v}) \mathrm{SDS}$ at $68{ }^{\circ} \mathrm{C}$ for $20 \mathrm{~min}$. The detections were performed according to the manufacturer's protocol (Roche Diagnostics). The resulting materials were analyzed in a LAS-1000 image analyzer (Fuji Photo Film Co., Tokyo).

RNA bLOT ANALYSIS. For Northern blot analysis, apple leaves were collected from greenhouses at our research center in Morioka, Japan. Total RNA was isolated from leaves of transgenic and nontransgenic 'Orin' apples in the growing season using the CTAB method as described by Kotoda et al. (2000). Twenty micrograms of the total RNA was separated on $1.2 \%$ SeaKem GTG agarose gel containing 5.0\% (v/v) formaldehyde, after which the gel was blotted on Hybond-N+. Hybridization was performed in DIG Easy Hyb at $50{ }^{\circ} \mathrm{C}$ for $16 \mathrm{~h}$ with a DIG-labeled PCR probe using MdTFL1 cDNA as a template. The primer set used for preparing the probe was MdTFL-2S and -2A (Fig. 1B). This probe detects only transcripts of the transgene because no expression of endogenous MdTFL1 was detected in nontransgenic 'Orin' apple leaves examined in RNA blot analysis. As an internal control, the expression of the histone $\mathrm{H} 3$ gene (Histone H3) was measured. The wash and detection was performed in the same manner as that used for DNA.

REVERSE TRANSCRIPTION (RT)-PCR ANALYSIS. Total RNAs were isolated from cultured tissues of each transgenic line and a nontransgenic control using the SV total RNA Isolation System (Promega, Madison, Wis.). A specific primer (5'-TTG TGG CAT ACA TTG TAA ATA-3', 21 bp) for MdTFL1 (Fig. 1B; Table 1) and a random primer (nonadeoxyribonucleotide mixture) for AFL1, AFL2 (apple orthologues of LEAFY; Wada et al., 2002), $M d A P 1$ (an apple orthologue of APETALA1; Kotoda et al., 2000,
Table 1. Gene-specific primer sets used for reverse transcription PCR analyses of transgenic lines.

\begin{tabular}{ll}
\hline Primer & \multicolumn{1}{c}{ Oligonucleotide } \\
\hline MdTFL1 & \\
Sense primer & 5'-CTC TTA AAA TGA AAA GAG CCT CGG-3' (24 mers) \\
Antisense primer & 5'-TTG TGG CAT ACA TTG TAA ATA-3' (21 mers) \\
AFL1 & \\
Sense primer & 5'-GCA CCC GTT CAT TGT GAC GG-3' (20 mers) \\
Antisense primer & 5'-GCC CAA AAT CTC TCG CCC-3' (18 mers) \\
AFL2 & \\
Sense primer & 5'-GCA CCC GTT CAT TGT GAC GG -3' (20 mers) \\
Antisense primer & 5'-CTT ATC AGT TAT ATT GAA GCG-3' (21 mers) \\
MdAP1 & \\
Sense primer & 5'-ATG GGG AGA GGT AGA GTT CAG CTT-3' (24 mers) \\
Antisense primer & 5'-TTA GAC ACA TGG AAG TGG CTG TGG-3' (24 mers) \\
Histone H3 & \\
Sense primer & 5'-TGA AGA AGC CCC ACA GAT A-3' (19 mers) \\
Antisense primer & 5'-ACA CAA GAA ACT ATA AAC C-3' (19 mers) \\
\hline
\end{tabular}

2002), and the apple Histone $H 3$ (internal control) were used in $\mathrm{RT}$ reactions $\left(30{ }^{\circ} \mathrm{C}\right.$ for $10 \mathrm{~min}, 42^{\circ} \mathrm{C}$ for $50 \mathrm{~min}, 99^{\circ} \mathrm{C}$ for $5 \mathrm{~min}$ ) with $1 \mu \mathrm{g}$ of total RNA. Because the specific antisense primer for MdTFL1 was designed between the positions +670 and +690 of MdTFL1 cDNA, $\approx 100$ bp downstream the region used for vector construction, the primer specifically anneals to the endogenous MdTFL1 mRNA to synthesize the first strand cDNA in a RT reaction. RT-PCR products of MdTFLl (699 bp), AFL1 (583 bp), AFL2 (564 bp), MdAPl (613 bp), and Histone H3 (371 bp) were identified using gene-specific primer sets shown in Table 1. Conditions of amplification for each primer set were as follows: 1 cycle of $300 \mathrm{~s}$ at $94{ }^{\circ} \mathrm{C}, 40$ cycles of $30 \mathrm{~s}$ at $94{ }^{\circ} \mathrm{C}$, $30 \mathrm{~s}$ at $53{ }^{\circ} \mathrm{C}$, and $60 \mathrm{~s}$ at $72{ }^{\circ} \mathrm{C}$ for MdTFLl and Histone H3; 1 cycle of $300 \mathrm{~s}$ at $94{ }^{\circ} \mathrm{C}, 40$ cycles of $30 \mathrm{~s}$ at $94{ }^{\circ} \mathrm{C}, 30 \mathrm{~s}$ at 50 ${ }^{\circ} \mathrm{C}$, and $60 \mathrm{~s}$ at $72{ }^{\circ} \mathrm{C}$ for $A F L 1$ and $A F L 2 ; 1$ cycle of $300 \mathrm{~s}$ at 94 ${ }^{\circ} \mathrm{C}, 40$ cycles of $30 \mathrm{~s}$ at $94{ }^{\circ} \mathrm{C}, 30 \mathrm{~s}$ at $55^{\circ} \mathrm{C}$, and $60 \mathrm{~s}$ at $72{ }^{\circ} \mathrm{C}$ for $M d A P 1$. Amplified products were separated on $1.5 \%(\mathrm{w} / \mathrm{v})$ SeaKem ME agarose gel (Cambrex Bio Science) in 1×TAE buffer. DNA was then stained in an ethidium bromide solution at $1.0 \mu \mathrm{g} \cdot \mathrm{mL}^{-1}$ for $20 \mathrm{~min}$.

Pollen Viability test. Anthers from the transgenic lines and the nontransgenic control 'Orin' apple were collected in a $1.5-\mathrm{mL}$ tube and incubated at $25{ }^{\circ} \mathrm{C}$ with silica gel for the dehiscence of anther. Thereafter, pollen was plated on $1 \%(\mathrm{w} / \mathrm{v})$ agar containing $17 \%(\mathrm{w} / \mathrm{v})$ sucrose and then incubated at $25^{\circ} \mathrm{C}$ for pollen germination. The pollen germination was photographed using light microscopy (Nikon Corp., Tokyo).

\section{Results}

Transformation OF APPLE WITH 35S::MdTFL1 ANTISENSE GENE. To clarify the function of MdTFL1 (GenBank accession no. AB052994), a putative orthologue of arabidopsis TFL1, we produced transgenic apple trees with the MdTFL1 antisense gene driven by the cauliflower mosaic virus (CaMV) 35S promoter for the purpose of suppressing the expression of endogenous MdTFL1. The transformation vector contained neomycin phosophotransferase II gene (nptII), which detoxifies antibiotics such as neomycin, kanamycin, G418, and paromomycin. Thus, kanamycin sulfate was used as a selective agent to obtain the transformed shoots of the apple cultivar Orin. About 2000 leaf disks of the 'Orin' apple were used in the Agrobacterium-mediated transformation. Kanamycin-resistant shoots regenerated from five independent leaf disks were cultured in the proliferating medium after selection. The putatively transformed five kanamycin-resistant shoots were micropropagated in the proliferating medium and then each line was multiplied by grafting individual shoots in tissue culture 
to 'JM8' dwarfing rootstocks, giving rise to one to four clones per line (Table 2). Numbers following the line (e.g., 303-1 and 303-4 in Table 2) mean clones multiplied by greenwood grafting as described above. The nontransformed 'Orin' apples were also grafted onto 'JM8' or seedlings as controls in the same way as transformed lines. The grafted transformed lines and nontransformed control plants started to be grown in the greenhouse for further analysis at the same time for the greenwood grafting. Insertion of the transgene was confirmed by a PCR with specific primers for $n p t I I$ and MdTFLI, revealing that three independent transformants (lines 303, 614, and 705) and two escapes (lines 837 and 850) were produced (Table 2).

DNA BLOT ANALYSIS OF TRANSGENIC LINES. DNA blot analysis was performed for transgenic lines using DIG-labeled nptII and MdTFL1 PCR probes to demonstrate the copy number of the transgene. DNA blot probed with an nptII cDNA fragment showed that line 614 has one copy and lines 303 and 705 have two copies of the transgene (Fig. 2). Every line has a common 2.9-kb fragment derived from the region between two BamHI sites of T-DNA on the lane of BamHI digestion (Fig. 1A; Fig. 2, arrowhead). DNA blot probed with an MdTFL1 cDNA fragment reflected the same result as that with nptII (data not shown).

Precocious flowering of transgenic apple trees. Transgenic line 705-1 produced a solitary flower only 8 months after the transfer to the green house (Fig. 3A; Table 2), despite the previous observation that apple seedlings flower naturally after 7 to 8 years (Zimmerman, 1972). Other lines also showed precocious flowering, ranging from 11 to 25 months after the transfer to the greenhouse (Table 2). In contrast, no flowering took place in the nontransgenic controls grafted onto seedlings for $\approx 6$ years (Table 2, control-1). In addition, nontransgenic controls grafted onto 'JM8' dwarfing rootstocks have not flowered for 5 years in the greenhouse (Table 2, control-2). After breaking the first dormancy, six transgenic apple trees, including lines 303 and 705 , produced some solitary flowers on their leaf axils and at the tops of 2-year-old or current shoots (Fig. 3B). Normal apple trees produce many clusters comprised of about five flowers on their fruit-bearing shoots. These transgenic lines also produced clusters comprised of a normal number of flowers from the second leaf (Fig. 3 B and C). Interestingly, line 705 showed an ever-flowering habit as well as reduced juvenility (Fig. 3C). As for leaf morphology, line 303 had round, more serrated leaves, and line 705 had leaves with much smaller stipules than those of the controls (Fig. 3D).

In line 303, the branches were upright and relatively short due to retarded growth compared to the other lines and nontransgenic controls (Table 2). The tree vigor of lines 614 and 705 was weaker as a whole, and the branching was a little more complicated than those of the nontransgenic controls because foliar buds were often converted to floral buds. A diagram of the growth habits of the nontransgenic control (WT) and the transgenic line (35S:: MdTFL1-AS) is shown in Fig. 4. In apple, flowers are produced on terminal inflorescences (Fig. 4B) after going through the juvenile phase (Fig. 4A). In contrast, the transgenic line with a 35S::MdTFL1 antisense construct flowered within 1 year after the transfer to the greenhouse (Fig. 4C). The conversion of foliar buds (shown in brown arrowheads) into floral buds (shown in pink arrowheads) leads to the cessation of shoot growth, resulting in a change in the plant architecture to shorter and more complicated branches (Fig. 4 D).

FLOWER AND FRUIT DEVELOPMENT OF THE MOST PRECOCIOUS FLOWERING LINE. The first flower of the most precocious line,
Table 2. Phenotype of transformed 'Orin' apples with the MdTFL1 antisense gene.

\begin{tabular}{cccccc}
\hline $\begin{array}{l}\text { Transgenic } \\
\text { line }^{\mathrm{z}}\end{array}$ & $\begin{array}{c}n p t I I \\
\text { gene }^{\mathrm{y}}\end{array}$ & $\begin{array}{c}\text { Transgene } \\
\text { RNA }^{\mathrm{x}}\end{array}$ & $\begin{array}{c}\text { Time to first } \\
\text { flowering } \\
\text { (months) }\end{array}$ & $\begin{array}{c}\text { Growth } \\
\text { habit }^{\mathrm{v}}\end{array}$ & $\begin{array}{c}\text { Grafted } \\
\text { year }\end{array}$ \\
\hline $\begin{array}{c}\text { Control-1 } \\
\text { Control-2 }\end{array}$ & ND & ND & 69 & N & 1997 \\
$303-1$ & + & NT & - & N & 2000 \\
$303-4$ & + & + & 11 & SB & 2000 \\
$705-1$ & + & + & 11 & SB & 2000 \\
$705-2$ & + & + & 8 & W, SB & 2000 \\
$705-3$ & + & + & 13 & W, SB & 2000 \\
$705-4$ & + & + & 11 & W, SB & 2000 \\
$614-1$ & + & + & 25 & W, SB & 2000 \\
$837-1$ & ND & NT & - & W & 2001 \\
$837-2$ & ND & NT & - & N & 2002 \\
$850-1$ & ND & NT & - & N & 2002 \\
$850-2$ & ND & NT & - & N & 2002 \\
$850-3$ & ND & NT & - & N & 2002 \\
\hline
\end{tabular}

zThree independently regenerated nontransformed 'Orin' apples were grafted on seedlings (control-1) or 'JM8' rootstocks (control-2). Numbers following the line (e.g., 303-1 and 303- 4 ) mean clones multiplied by greenwood grafting of tissue-cultured shoots.

yDNA was extracted from the leaves, and PCR was performed to detect nptII genes.

Total RNA was extracted from the leaves, and Northern blot analysis was performed to detect the transgene RNA.

${ }^{\text {w} M o n t h s ~ c o u n t e d ~ f r o m ~ g r a f t i n g ~ a n d ~ t r a n s f e r ~ t o ~ t h e ~ g r e e n h o u s e . ~-~, ~ n o t ~ f l o w-~}$

ered.
v, normal growth habit; SB, short branch; W, weak tree vigor.

ND, not detected; NT, not tested; +, detected.

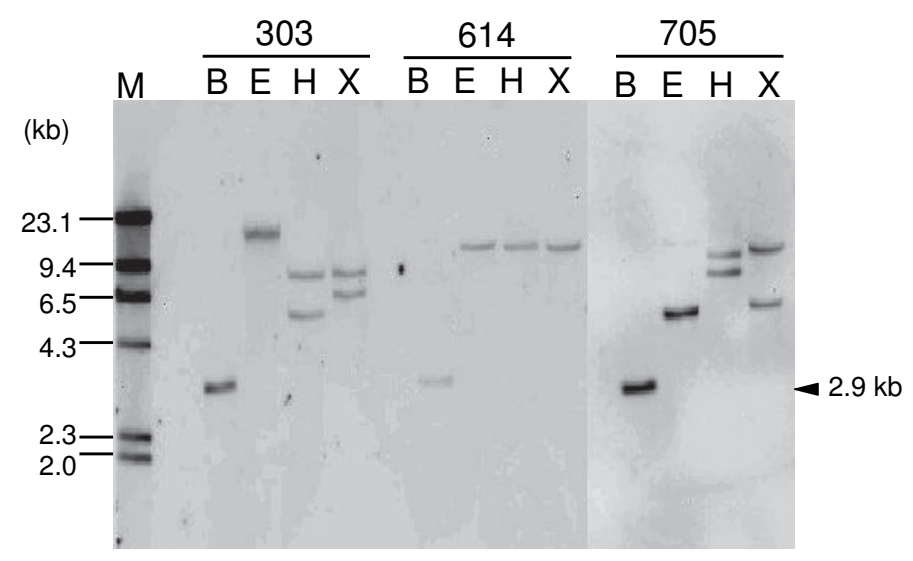

Fig. 2. Southern blot analysis of transformed 'Orin' apples with the MdTFL1 antisense gene. Genomic DNA $(10 \mu \mathrm{g})$ was isolated from the leaves of three transformants (lines 303-1, 614-1, and 705-1), digested individually with BamHI, EcoRI, HindIII, or XbaI, and then separated on $0.8 \%(\mathrm{w} / \mathrm{v})$ agarose gel. The DNA bands were transferred to Hybond-N+ and hybridized with a digoxigenin (DIG)-labeled PCR probe encoding the nptII. BamHI, EcoRI, HindIII, and XbaI were the enzymes with no recognized positions in the region used for $n p t I I$ probe (Fig. 1A). Hybridization was performed in DIG Easy Hyb (Roche Diagnostics, Mannheim, Germany) at $42{ }^{\circ} \mathrm{C}$ for $16 \mathrm{~h}$, followed by two washes in $0.5 \times \mathrm{SSC}$ containing $1 \%(\mathrm{w} / \mathrm{v}) \mathrm{SDS}$ at $68^{\circ} \mathrm{C}$ for $20 \mathrm{~min}$. A DIG-labeled DNA Molecular Weight Marker II (Roche Diagonistics) was used as a size marker; $\mathrm{M}=$ molecular weight marker, $\mathrm{B}=$ Bam HI, $\mathrm{E}=$ EcoRI, $\mathrm{H}=$ HindIII, $\mathrm{X}=$ XbaI.

705-1, had no stamens (Fig. 5A), whereas most of the flowers emerging after the following season were normal in appearance (Fig. 5B), like those of the nontransgenic control 'Orin' apple (Fig. 5C). To confirm the fertility of transgenic apple trees that showed precocious flowering, we carried out pollination between transgenic apple trees and other nontransgenic apple cultivars. Line 705-1, pollinated with the Japanese apple cultivar Sansa, set some fruit (Fig. 5D). On the other hand, the representative line, 705-1, was used to pollinate apple cultivars Sansa and McIntosh Wijcik because pollen from the precocious lines (Fig. 5K) had an ability to germinate on agar plates as the controls (Fig. 5L), resulting in the setting of some fruit (Fig. 5E). The development 


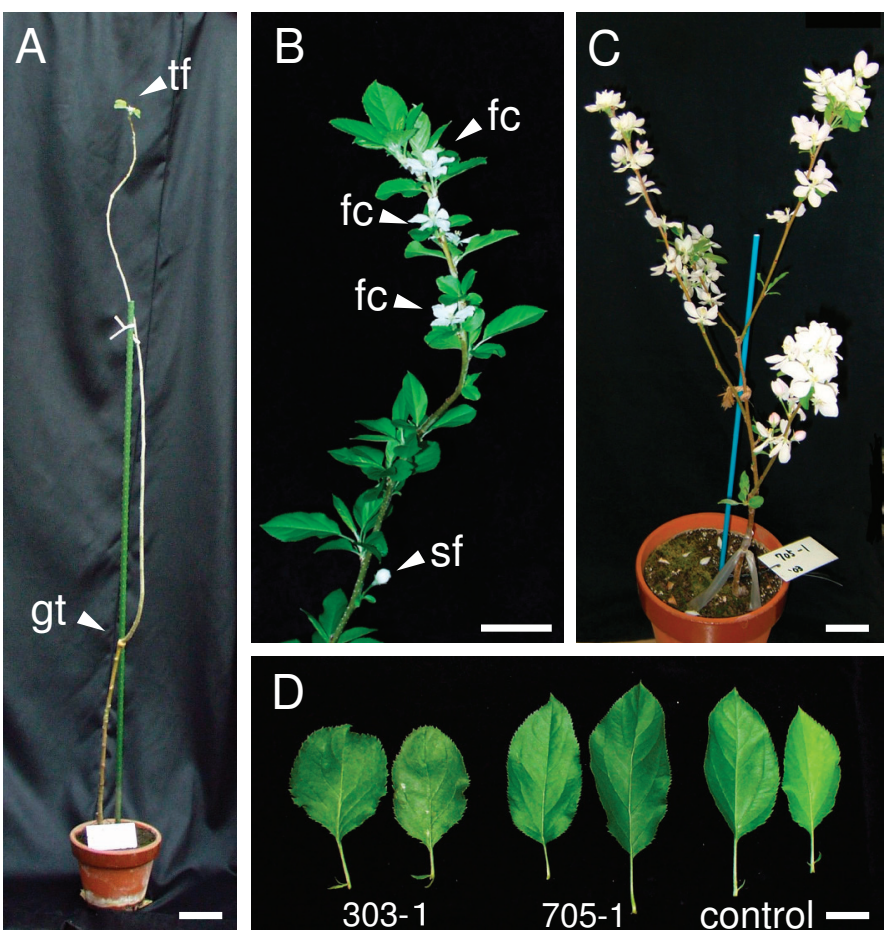

Fig. 3. Precocious flowering of transgenic 'Orin' apples by constitutive expression of the MdTFL1 antisense gene. (A) Eight-month-old transgenic line 705-1 grafted onto 'JM8' dwarfing rootstock; terminal flower (tf) and graft union (gt) are indicated by arrowheads. (B) Twelve-month-old transgenic line 705-1 after the breaking of the first dormancy; solitary flower (sf) and flower clusters (fc) are indicated by arrowheads. (C) Three-year-old transgenic line produced by grafting a scion of line 705-1; an ever-flowering characteristic is observed. (D) Leaves from transgenic lines 303-1 (left), 705-1 (center), and a nontransgenic control (right) [scale bars: (A) $10 \mathrm{~cm}$, (B) and (C) $5.0 \mathrm{~cm}$, (D) $2.0 \mathrm{~cm}$ ].

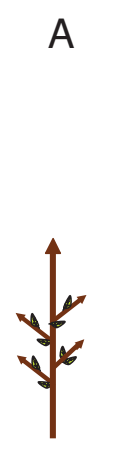

WT

(2 years old)

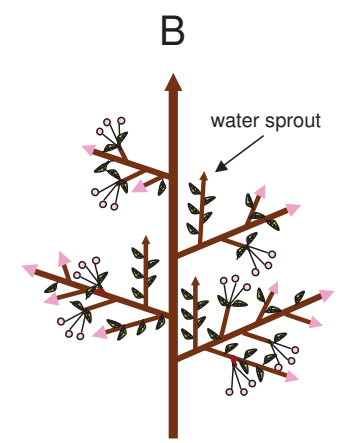

35S::MdTFL1-AS (1 year old)

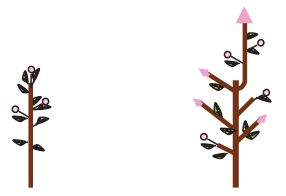

C

35S::MdTFL1-AS ( 2 years old)

$$
\text { \&े }
$$

Fig. 4. Schematic representation of the phenotype of a wild-type and a transgenic apple with a $35 S:$ MdTFL1 antisense gene (AS). The expression of 35S: MdTFL1-AS causes changes in the plant architecture. (A) Two-year-old wildtype (WT) plant; no flowers are present on shoots during the juvenile phase. (B) Seven to 8-year-old wild-type (WT) plant; flowers are produced on terminal inflorescences after the end of the juvenile phase; no flowers are present on vegetative shoots growing upright (water sprout) even in the reproductive phase. (C) One-year-old precocious line expressing 35S::MdTFL1-AS; flowers are present at the top of the shoot (terminal inflorescence) and in leaf axils, resulting in the termination of the shoot growth. (D) Two-year-old precocious line. The tree vigor becomes weak and the plant architecture is changed due to the replacement of shoots by flowers. New growth is initiated from axillary meristems proximal to the terminal inflorescence. Foliar buds and floral buds are shown in brown and pink arrowheads, respectively. of the transgenic fruit appeared normal (Fig. 5 D and E) compared to the nontransgenic controls grown normally in the field (Fig. F). Fruit from line 705-1 were harvested about 6 months after pollination (Fig. 5G). The skin color and the aroma of the transgenic fruit were almost the same as those of nontransgenic 'Orin' fruit, although the size of the transgenic fruit was about one-third that of fruit of the nontransgenic controls grown in the field. Some transgenic fruit were seeded (Fig. $5 \mathrm{H}$ ), and others were often seedless. Interestingly, the precocious line had a marked tendency to set some fruit without fertilization (Fig. 5I). In line 705 , the transition to flowering often occurred and floral buds (fb) were produced on growing current shoots where it hardly occurs in the nontransgenic control plants (Fig. 5J).

EXPRESSION ANALYSES OF TRANSGENIC LINES. Transgene expression in the leaves of transformants was analyzed by RNA blot hybridization probed with MdTFL1 (Fig. 6A). The probe was prepared by direct labeling of amplification products of MdTFL1 with DIG-dUTP in a PCR in the same manner as that prepared in DNA blot analysis. This probe detected only the transcripts of the transgene in apple leaves because no expression of endogenous MdTFL1 was detected in the nontransgenic control 'Orin' apple leaves examined in RNA blot analysis (Fig. 6A, cont), although it can detect both sense and antisense $M d T F L 1$ RNA. In our previous work, it was also demonstrated that MdTFLl was not expressed in leaves (Kotoda and Wada, 2005). The transgene expression was relatively strong in transgenic lines 303-1 and 705-1 compared to line 614-1 and correlated inversely with the time to flowering in transformants (Fig. 6A; Table 2). To detect the expression of endogenous MdTFL1, RT-PCR was performed as shown in Fig. 6B. Total RNAs from tissue cultures of some shoots in each line were used because MdTFL1 is normally expressed in vegetative shoot apices, not in leaves (Kotoda and Wada, 2005). Because an antisense primer specific to MdTFL1 was used for the first strand cDNA synthesis in a RT reaction, the primer would anneal to endogenous sense MdTFL1 mRNA, not to antisense one derived from the trangene. In addition, the primer site was out of the region of the MdTFL1 cDNA used for the $35 S:: M d T F L 1$ antisense construct (Fig. 1B). Thus, the 699 bp RT-PCR product was specific to endogenous MdTFL1. As expected, the expression of endogenous MdTFL1 was suppressed in the transgenic lines as compared to the nontransgenic control 'Orin' apple, although it was still detectable in the transgenic lines (Fig. 6B). To examine the effect of the antisense suppression of MdTFL1 on the other genes involved in the flowering of apple, the expression of $A F L 1, A F L 2$, and MdAP1 (MdMADS5) in transgenic lines was analyzed by RT-PCR using the RNAs from the tissue culture of shoots (Fig. 6C). AFL1 and AFL2 are apple orthologues of FLORICAULA/LEAFY (Kotoda et al., 2000; Wada et al., 2002), and $M d A P 1$ is an apple orthologue of APl (Kotoda et al., 2000, 2002; Yao et al., 1999). AFL1 was up-regulated in line 303 (Fig. 6C), although $A F L 1$ is not expressed in the vegetative tissues but specifically in floral shoot apices in normal apple (Wada et al., 2002). For AFL2, which is normally expressed in both vegetative and floral shoot apices, the gene expression was seen in the transgenic lines as well (Fig. 6C). The expression of AFL2 was relatively high in line 705, which flowered the earliest of all the transformants. The expression of $M d A P 1$ was not detected in either transgenic lines or a nontransgenic control (Fig. 6C). In this expression analysis, the histone $\mathrm{H} 3$ gene (Histone H3) of apple was adopted as an internal control. 

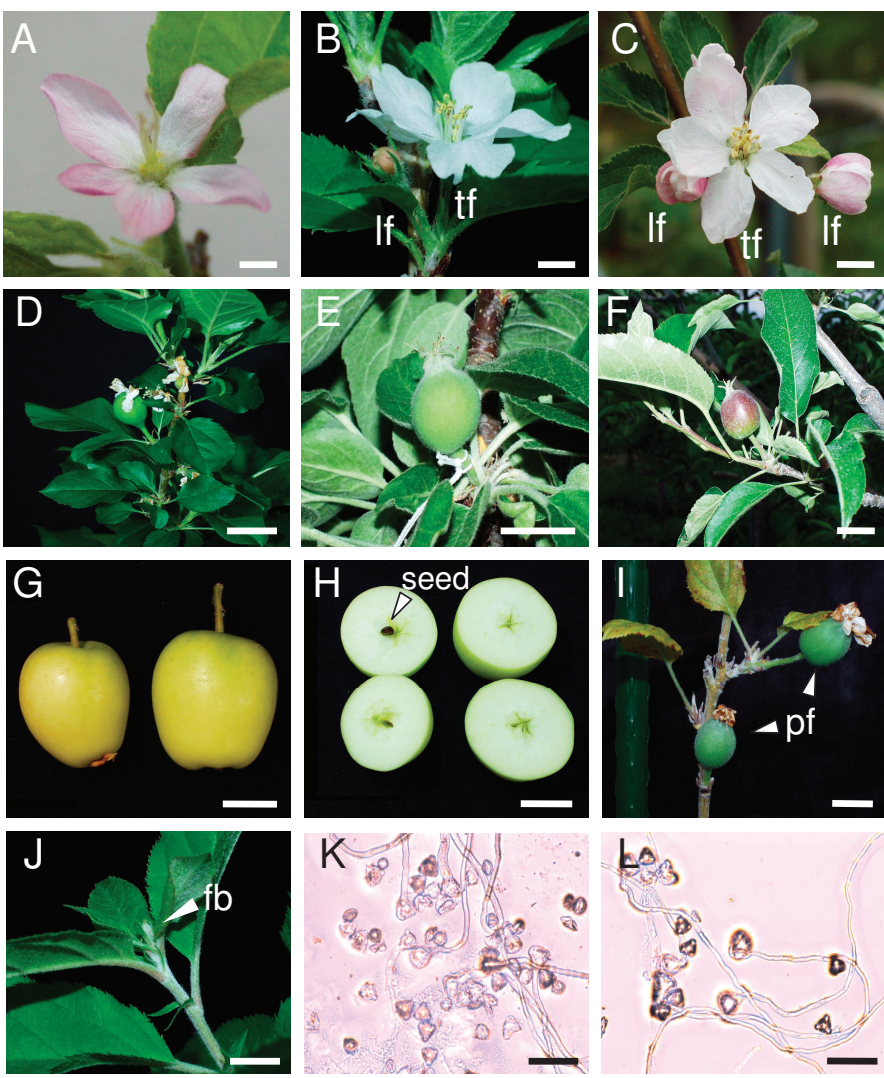

Fig. 5. Flowers, fruit, and pollen viability of the transgenic 'Orin' apples with a $35 S:: M d T F L 1$ antisense gene. (A) to (C) Flowers of transgenic and nontransgenic 'Orin' apples. (A) Close-up of the solitary flower of the transgenic line 705-1 shown in Fig. 3A. (B) Close-up of the flower cluster of the transgenic line 705-1 shown in Fig. 3B. (C) Close-up of flowers from a control 'Orin' apple grown in the field; tf and if in (B) and (C) indicate terminal flower and lateral flower, respectively. (D) to (F) Fruit of transgenic and nontransgenic 'Orin' apples. (D) Four-week-old young fruit of transgenic 705-1 crossed with 'Sansa'. (E) Four-week-old young fruit of 'McIntosh Wijcik' crossed with line 705-1. (F) Four-week-old young fruit of the control plant. (G) to (I) Fruit development with and without pollination. (G) Mature fruit with pollination. (H) Inside of the fruit in $(\mathrm{G})$; left $=$ fruit having a seed (arrowhead), right = seedless fruit. (I) Young fruit of line 705 that developed without pollination; arrowheads indicate parthenocarpic fruit (pf). (J) to (L) Pollen germination of transgenic and nontransgenic control plants on $1 \%(\mathrm{w} / \mathrm{v})$ agar containing $17 \%(\mathrm{w} / \mathrm{v})$ sucrose. (J) Floral bud (fb) produced on the top of the growing current shoo before the dormant period in the transgenic precocious line, although floral bud differentiation normally occurs after the cessation of shoot growth. (K) Pollen from line 705-1. (L) Pollen from nontransgenic 'Orin' apple [scale bars: (A) to (C) $0.5 \mathrm{~cm}$, (D) to (I) $2.0 \mathrm{~cm}$, (J) $3.0 \mathrm{~cm}$, (K) and (I) $100 \mu \mathrm{m}]$.

\section{Discussion}

ANTISENSE EXPRESSION OF MdTFL1 INDUCED THE PRECOCIOUS FLOWERING AND DEVELOPED FRUIT IN APPLE. There are two ways to produce plants with precocious flowering. One is the constitutive expression of genes that promote flowering, such as $L F Y$, $A P 1$, and $F T$. The other is the suppression of genes that delay flowering, such as TFL1, by antisense expression, co-suppression, or RNA interference (RNAi). We have shown here that the antisense expression of MdTFLl effectively induces precocious flowering in transgenic apple. The transgenic lines 303 and 705 first flowered 8 to 13 months after the transfer to the greenhouse, and line 614 first flowered 25 months after the transfer to the green house, in contrast to the nontransgenic controls, one of which first flowered at 69 months after the transfer to the greenhouse (Table 2). It is certain that the precocity of the transgenic lines
A

B
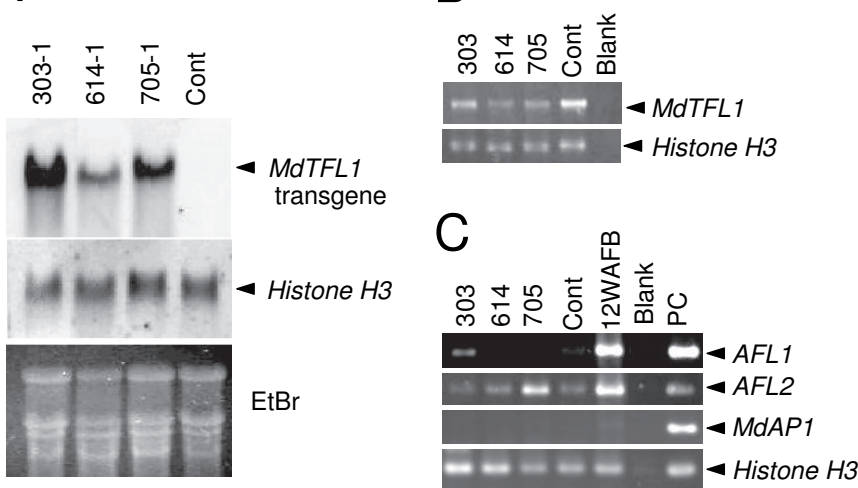

Fig. 6. Expression analyses of transgenic 'Orin' apples with a $35 S:$ :MdTFL1 antisense gene by Northern blot and reverse transcription (RT)-PCR. (A) Northern blot analysis of transgene expression in the leaves of each transgenic line (lines 303-1, 614-1, and 705-1); hybridization was performed in DIG Easy Hyb (Roche Diagonistics, Mannheim, Germany) at $50{ }^{\circ} \mathrm{C}$ for $16 \mathrm{~h}$ with a digoxigenin (DIG)-labeled PCR probe using MdTFL1 cDNA as a template. (B) RT-PCR analysis for the expression of the endogenous MdTFL1 in the shoots of tissue culture of each transgenic line (lines 303,614, and 705); a specific antisense primer for MdTFL1 was used in a RT reaction, and then PCR was performed with primers specific to endogenous MdTFL1. (C) RT-PCR analysis of apple genes involved in flowering using RNAs from shoots of tissue culture of each transgenic line (lines 303, 614, and 705). AFL1 and AFL2 are apple homologues of FLORICULA/LEAFY and MdAP1 is an apple homologue of APETALA1. In the expression analyses, nontransgenic 'Orin' apple (cont) and histone $\mathrm{H} 3$ gene (Histone H3) were used as a control plant and an internal control of gene expression, respectively $; \mathrm{EtBr}=$ ethidium bromide, $\mathrm{PC}=$ positive control (plasmid containing each gene).

was due to the effect of the antisense expression of MdTFL1 because the nontransgenic control 'Orin' apples grafted onto seedlings (control-1) or 'JM8' dwarfing rootstocks (control-2) did not initiate flowering for at least 5 years after the transfer to the greenhouse (Table 2). The expression level of the transgene was relatively high in lines 303 and 705, which have two copies of the transgene, as compared to line 614 , which has one copy (Fig. 2, Fig. 6A). These results show that the expression level of the transgene is correlated with the precocity of the transformants. As expected, the expression of endogenous MdTFL1 in the shoots was suppressed in transgenic lines as compared to the nontransgenic control apple (Fig. 6B), indicating that MdTFL1 intrinsically represses the transition to flowering and maintains the juvenile phase in apple. The knockdown of the MdTFL1 gene by co-suppression or RNAi would induce much more precocity, based on the finding that the endogenous MdTFL1 in the transformants was not suppressed completely by the antisense method. Some defects in the flower organs of transgenic lines, such as the lack of stamens and pistils or a decreased number of flowers per cluster, can be attributed to the underdevelopment of floral buds but not directly to the function of MdTFLI because such defects or unusual solitary flowers were rarely observed as they grew.

Most flowers of the transgenic lines had functionally normal reproductive organs, resulting in normal fruit that contained several seeds (Fig. $5 \mathrm{G}$ and $\mathrm{H}$ ). In fact, it was found by crossing tests that line 705 had both pollen and seed viability. The apple cultivar Sansa was crossed by transgenic line 705, and then seedlings from the crossing were obtained and the inheritance of the transgene was preliminarily confirmed by a PCR (data not shown). These results show that the precocious line with a 35S::MdTFL1 antisense construct could be both a pollen and seed parent of apple in cross breeding. The precocious line had 
a marked tendency to set parthenocarpic fruit [pf (Fig. 5I)], suggesting that the antisense expression of MdTFL1 may reinforce parthenocarpy in 'Orin' apple since the original 'Orin' apple occasionally produces parthenocarpic seedless fruit. Several apple mutants, such as 'Noblow', 'Wellington Bloomless', and 'Spencer Seedless', produce apetalous flowers that develop into parthenocarpic seedless fruit (Stout, 1929). However, flowers from the transgenic line or nontransgenic control 'Orin' apple had four normal floral organs (sepals, petals, stamens, and pistils) (Fig. 5 $\mathrm{B}$ and $\mathrm{C}$ ), unlike the apetalous flowers of those mutants.

Floral bud differentiation in transgenic line 705 occurred several times over a period of at least 4 months, and flowers were produced sequentially during the period (Fig. 3C). In addition, line 705 produced floral buds and flowers on the growing current shoots (Fig. 5J). Shoots that produced flowers ceased vegetative growth, causing the tree to become less vigorous and to develop shorter branches than the controls (Fig. $4 \mathrm{C}$ and D). In contrast, normal apple trees neither induce floral bud differentiation on the growing vegetative shoot (Fig. 4B, water sprout) nor come into flower even on reproductive shoots growing after anthesis in the current season; rather, they flower naturally after breaking dormancy the following spring season. Antisense expression of MdTFL1 frequently shortened the period of flower development, possibly by abolishing the repression of flower development by dormancy. The observation is consistent with the ever-flowering characteristic of the line 705. These findings suggest that MdTFL1 affects flower development and plant architecture as well as flower induction in apple.

FACTORS CONTROLLING THE TRANSITION FROM THE JUVENILE TO THE REPRODUCTIVE PHASE. At our institute, floral bud differentiation begins in early July; at this time, MdTFL1 mRNA is expressed strongly in apices of current apple shoots (Kotoda and Wada, 2005). The expression of MdTFL1, however, decreases gradually until mid-December, paralleling the development of flower primordia. Previously, we reported that the expression of the AFL1 gene was detected after the onset of floral bud differentiation and that MdAP1 mRNA appeared concurrent with sepal formation (Kotoda et al., 2000; Kotoda and Wada, 2005; Wada et al., 2002). AFL1 or AFL2 was up-regulated in the precocious line 303 or 705 , respectively, as compared to the nontransgenic control, whereas $M d A P 1$ was not expressed in those transgenic lines (Fig. 6C). Thus, the down-regulation of MdTFL1 might trigger the up-regulation of $A F L 1$ and/or AFL2 in apical buds, resulting in flower induction in apple, although the up-regulation of $A F L 1$ or $A F L 2$ was transient in the transgenic lines with a $35 S:$ : MdTFL1 antisense construct. It is interesting that the juvenile and/or vegetative phases can be regulated by only a TFL1-like gene even though their maintenance is one of the most important events in the early stage of development in woody plants. Based on these results, MdTFL1 must be one of the factors controlling the transition from the juvenile/vegetative to the reproductive phase in apple.

We produced several transgenic apple trees that ectopically expressed genes possibly involved in flowering, but there were few transgenic apple trees that markedly induced precocious flowering other than those expressing MdTFL1 antisense RNA. A decade ago, it was found that the juvenile phase of an aspen hybrid of two poplar species (Populus tremula L. X P.tremuloides Michx.) could be reduced using transgenic procedures by introducing arabidopsis $L F Y$ under the CaMV $35 \mathrm{~S}$ promoter (Weigel and Nilsson, 1995). Five-month-old shoots of transgenic aspen hybrids grown in tissue culture produced solitary flowers in the axils of normal leaves. However, Rottmann et al. (2000) reported that multiple lines of poplar over-expressing either $L F Y$ or PTLF (a poplar homologue of $L F Y$ ) did not show the early flowering phenotype that was expected. In fruit crops, transgenic citrus [C. sinensis $\mathrm{x}$ Poncirus trifoliata (L.) Raf.] expressing $L F Y$ or APl initiated flowering 12-20 months after the transfer to the greenhouse, resulting in normal, fertile flowers that set fruit and seeds, despite the observation that regenerated nontransformed plants initiated flowering only after 5 years of growth in the greenhouse (Peña et al., 2001). However, it is not clear whether there is a common mechanism of flower induction in citrus and apple because citrus, an evergreen fruit tree, is very different from apple, a deciduous fruit tree, in terms of growth and fruiting habits. In fact, unlike that of citrus, the constitutive expression of $M d A P 1$ or $A F L 1$ in apple does not cause precocious flowering except for the single instance of apple that expresses arabidopsis AP1 (N. Kotoda, unpublished data). Therefore, the competence of apple to respond to the constitutive expression of $A P 1$ - or $L F Y$-like genes might be lower than that of citrus. Together with the fact that only a few instances of precocious flowering in deciduous woody plants by over-expression of $L F Y$ or $A P I$ have been reported, $L F Y$ and $A P I$ may not be effective factors for breaking the juvenile and/or vegetative phases of deciduous fruit trees such as apple. Like TFL1, CEN, SP, and FT, the putative protein encoded by the $M d T F L 1$-shared sequence is similar to the mammalian phosphatidylethanolamine-binding proteins (PEBP), originally named for their ability to bind phospholipids in vitro (Schoentgen and Jolles, 1995). In mammals, PEBP is an inhibitor of Raf-1 kinase activity (Yeung et al., 1999). Several years ago, the crystal structure of CEN was determined, suggesting that the biological effects of CEN arise from its ability to form complexes with phosphorylated ligands (Banfield and Brady, 2000). In the Raf-1 system, RKIP, an SP homologue protein from mammals, binds to Raf1 as tomato SP binds to SPAK (SP-associated kinase) in the SP system (Pnueli et al., 2001; Yeung et al., 1999). MdTFL1 may also function by interacting with proteins like SPAK or by other factors involved in flowering.

In citrus, the over-expression of CiFT, a mandarin orange (Citrus unshiu Marc.) homologue of FT, induced precocious flowering 3-22 months after the transfer of the transgenic plants to the greenhouse, which indicates that CiFT has a key role in the regulation of flower induction (T. Endo, in preparation). FT is a member of the CETS family and has conserved motifs that contribute to the conformation of the ligand-binding site, but its function is antagonistic to TFL1. Studies of factors that interact with CETS genes are needed to clarify the mechanism that underlies the transition to flowering in woody plants.

\section{Conclusion}

For the first time in the study of deciduous fruit trees, we have shown how effectively the antisense expression of MdTFL1 induces the precocious flowering of apple. In addition, we have shown that MdTFL1 has a key role in the regulation of juvenility, flower induction, and flower development in apple. The reduction of the generation time by the use of this transgenic approach to suppress endogenous TFL1-like genes may be applicable not only to fruit trees but also to the other woody plants that have a long juvenile period. The future use of these techniques should be advantageous in breeding, crop production, and basic research, e.g., molecular studies on woody plants, including fruit trees. 


\section{Literature Cited}

Aldwinckle, H.S. 1975. Flowering of apple seedlings 16-20 months after germination. HortScience 10:124-126.

Amaya, I., O.J. Ratcliffe, and D.J. Bradley. 1999. Expression of CENTRORADIALIS (CEN) and CEN-like genes in tobacco reveals a conserved mechanism controlling phase change in diverse species. Plant Cell 11:1405-1417.

Banfield, M.J. and R.L. Brady. 2000. The structure of Antirrhinum centroradialis protein $(\mathrm{CEN})$ suggests a role as a kinase regulator. J. Mol. Biol. 297:1159-1170.

Bradley, D., R. Carpenter, L. Copsey, C. Vincent, S. Rothstein, and E. Coen. 1996. Control of inflorescence architecture in Antirrhinum. Nature 379:791-797.

Bradley, D., O. Ratcliffe, C. Vincent, R. Carpenter, and E. Coen. 1997. Inflorescence commitment and architecture in Arabidopsis. Science 275:80-83.

Foucher, F., J. Morin, J. Courtiade, S. Cadioux, N. Ellis, M.J. Banfield, and C. Rameau. 2003. DETERMINATE and LATE FLOWERING are two TERMINALFLOWERI/CENTRORADIALIS homologs that control two distinct phases of flowering initiation and development in pea. Plant Cell 15:2742-2754.

Hackett, W.P. 1985. Juvenility, maturation, and rejuvenility in woody plants. Hort. Rev. 7:109-155.

Jensen, C.S., K. Salchert, and K.K. Nielsen. 2001.ATERMINALFLOWER 1-like gene from perennial ryegrass involved in floral transition and axillary meristem identity. Plant Physiol. 125:1517-1528.

Kardailsky, I., V.K. Shukla, J.H. Ahn, N. Dagenais, S.K. Christensen, J.T. Nguyen, J. Chory, M.J. Harrison, and D. Weigel. 1999. Activation tagging of the floral inducer FT. Science 286:1962-1964.

Kender, W.J. 1974. Ethephon-induced flowering in apple seedlings. HortScience 9:444-445.

Kobayashi, Y., H. Kaya, K. Goto, M. Iwabuchi, and T. Araki. 1999. A pair of related genes with antagonistic roles in mediating flowering signals. Science 286:1960-1962.

Kotoda, N. and M. Wada. 2005. MdTFL1, a TFL1-like gene of apple, retards the transition from the vegetative to reproductive phase in transgenic Arabidopsis. Plant Sci. 168:95-104.

Kotoda, N., M. Wada, S. Komori, S. Kidou, K. Abe, T. Masuda, and J. Soejima. 2000. Expression pattern of homologues of floral meristem identity genes $L F Y$ and $A P 1$ during flower development in apple. J. Amer. Soc. Hort. Sci. 125:398-403.

Kotoda, N., M. Wada, S. Kusaba, Y. Kano-Murakami, T. Masuda, and J. Soejima. 2002. Overexpression of MdMADS5, an APETALA1-like gene of apple, causes early flowering in transgenic Arabidopsis. Plant Sci. 162:679-687.

Lavi, U., E. Lahav, C. Degani, and S. Gazit. 1992. The genetics of the juvenile phase in avocado and its application for breeding. J. Amer. Soc. Hort. Sci. 117:981-984.

Levy, Y.Y. and C. Dean. 1998. The transition to flowering. Plant Cell 10:1973-1989.

Mandel, M.A., C. Gustafson-Brown, B. Savidge, and M.F. Yanofsky. 1992. Molecular characterization of the Arabidopsis floral homeotic gene APETALA1. Nature 360:273-277.

Mandel, M.A. and M.F. Yanofsky. 1995. A gene triggering flower formation in Arabidopsis. Nature 377:522-524.

Mimida, N., W. Sakamoto, M. Murata, and F. Motoyoshi. 1999. TERMINAL FLOWER 1-like genes in Brassica species. Plant Sci. 142:155-162.

Nakagawa, M., K. Shimamoto, and J. Kyozuka. 2002. Overexpression of RCN1 and RCN2, rice TERMINAL FLOWER 1/CENTRORADIA$L I S$ homologs, confers delay of phase transition and altered panicle morphology in rice. Plant J. 29:743-750.

Ohshima, S., M. Murata, W. Sakamoto, Y. Ogura, and F. Motoyoshi. 1997. Cloning and molecular analysis of the Arabidopsis gene Terminal Flower 1. Mol. Gen. Genet. 254:186-194.
O'Rourke, D., J. Janick, and S. Sansavini. 2003. World apple cultivar dynamics. Chronica Hort. 43(3):10-13.

Piñeiro, M. and G. Coupland. 1998. The control of flowering time and floral identity in Arabidopsis. Plant Physiol. 117:1-8.

Pillitteri, L.J., C.J. Lovatt, and L.L. Walling. 2004. Isolation and characterization of a TERMINAL FLOWER homolog and its correlation with juvenility in citrus. Plant Physiol. 135:1-12.

Peña, L., M. Martin-Trillo, J. Juárez, J.A. Pina, L. Navarro, and J.M. Martínez-Zapater. 2001. Constitutive expression of Arabidopsis LEAFY or APETALAl genes in citrus reduces their generation time. Nature Biotechnol. 19:263-267.

Pnueli,L., L. Carmel-Goren, D. Hereven, T. Gutfinger,J.Alvarez, M. Ganal, D. Zamir, and E. Lifschitz. 1998. The SELF-PRUNING gene of tomato regulates vegetative to reproductive switching of sympodial meristems and is the ortholog of CEN and TFL1. Development 125:1979-1989.

Pnueli, L., T. Gutfinger, D. Hareven, O. Ben-Naim, N. Ron, N. Adir, and E. Lifschitz. 2001. Tomato SP-interacting proteins define a conserved signaling system that regulates shoot architecture and flowering. Plant Cell 13:2687-2702.

Ratcliffe, O.J., I. Amaya, C.A. Vincent, S. Rothstein, R. Carpenter, E.S. Coen, and D.J. Bradley. 1998. A common mechanism controls the life cycle and architecture of plants. Development 125:1609-1615.

Ratcliffe, O.J., D.J. Bradley, and E.S. Coen. 1999. Separation of shoot and floral identity in Arabidopsis. Development 126:1109-1120.

Rottmann, W.H., R. Meilan, L.A. Sheppard, A.M. Brunner, J.S. Skinner, C. Ma, S. Cheng, L. Jouanin, G. Pilate, and S.H. Strauss. 2000. Diverse effects of overexpression of $L E A F Y$ and $P T L F$, a poplar (Populus) homolog of LEAFY/FLORICAULA, in transgenic poplar and Arabidopsis. Plant J. 22:235-245.

Sadamori, S., Y. Yoshida, H. Murakami, and S. Ishizuka. 1963. New apple variety 'Fuji.' Bul. Hort. Res. Sta. Jpn. Ser. (C) 1:1-6.

Schoentgen, F. and P. Jollès. 1995. From structure to function: Possible biological roles of a new widespread protein family binding hydrophobic ligands and displaying a nucleotide binding site. FEBS Lett. 369:22-26.

Soejima, J., H. Bessho, S. Tsuchiya, S. Komori, K. Abe, and N. Kotoda. 1998. Breeding of Fuji and performance on JM rootstocks. Compact Fruit Tree 31:22-24.

Stout, A.B. 1929. The development of seedless fruits fruits by breeding. J. New York Bot. Garden 30:270-277.

Sung, S.-K., G.-H. Yu, and G. An. 1999. Characterization of MdMADS2, a member of the SQUAMOSA subfamily of genes, in apple. Plant Physiol. 120:969-978.

Visser, T. 1964. Juvenile phase and growth of apple and pear seedlings. Euphytica 13:119-129.

Visser, T. 1965. On the inheritance of the juvenile period in apple. Euphytica 14:125-134.

Visser, T. 1973. The effect of rootstock on growth and flowering of apple seedling. J. Amer. Soc. Hort. Sci. 98:26-28.

Wada, M., Q. Cao, N. Kotoda, J. Soejima, and T. Masuda. 2002. Apple has two orthologues of FLORICAULA/LEAFY involved in flowering. Plant Mol. Biol. 49:567-577.

Weigel, D., J. Alvarez, D.R. Smyth, M.F. Yanofsky, and E.M. Meyerowitz. 1992. $L E A F Y$ controls floral meristem identity in Arabidopsis. Cell 69:843-859.

Weigel, D. and O. Nilsson. 1995. A developmental switch sufficient for flower initiation in diverse plants. Nature 377:495-500.

Yao, J.-L., Y.-H. Dong, A. Kvarnheden, and B. Morris. 1999. Seven $M A D S$-box genes in apple are expressed in different parts of the fruit. J. Amer. Soc. Hort. Sci. 124:8-13.

Yeung, K., T. Seitz, S. Li, P. Janosch, B. McFerran, C. Kaiser, F. Fee, K.D. Katsanakis, D.W. Rose, H. Mischak, J.M. Sedivy, and W. Kolch. 1999. Suppression of Raf-1 kinase activity and MAP kinase signalling by RKIP. Nature 401:173-177.

Zimmerman, R.H. 1972. Juvenility and flowering in woody plants: A review. Hort. Sci. 7:447-455. 